\title{
Improved Sensitive High Performance Liquid Chromatography Assay for Glucosamine in Human and Rat Biological Samples with Fluorescence Detection
}

\author{
Alyaa Ibrahim and Fakhreddin Jamali \\ Faculty of Pharmacy and Pharmaceutical Science, University of Alberta, Edmonton, Canada. \\ Received, March 30, 2010; revised, May 9, 2001; accepted, May 12, 2010; published, May 14, 2010.
}

\begin{abstract}
Purpose. An improved HPLC method with fluorescence detection was developed and validated for determination of glucosamine in human and rat biological samples. Method. Aliquot of $0.1 \mathrm{~mL}$ plasma was spiked with mannosamine $\mathrm{HCl}$ as the internal standard (IS); proteins were precipitated with acetonitrile; the clear layer was derivatized with 9-fluorenylmethyl chloroformate $(8 \mathrm{mM}$ /acetonitrile $)$ in presence of borate 0.2 $\mathrm{M}$ buffer at $30^{\circ} \mathrm{C}$ for $30 \mathrm{~min}$. The excess derivatizing agent was removed with 1-aminoadamantane $\mathrm{HCl}(300$ $\mathrm{mM}$ in acetonitrile-water 1:1). Chromatographic separation was achieved on a C18 (100mm X $4.6 \mathrm{~mm}$, id $3 \mu \mathrm{m})$ reversed phase column using $0.1 \%$ acetic acid/acetoniltrile gradient mobile phase at $1 \mathrm{~mL} / \mathrm{min}$ flow rate. Glucosamine was determined in the plasma of a human and rats and also in rat urine. Results. The analytes were detected at excitation and emission wavelengths of 263 and $315 \mathrm{~nm}$, respectively. The assay was linear over the range of $0.05-20 \mu \mathrm{g} / \mathrm{mL}$ with a typical correlation coefficient of 0.999 and intra-day and inter-day coefficient of variation of $<15 \%$. The lowest limit of quantification was set at $50 \mathrm{ng} / \mathrm{mL}$. The recovery for glucosamine and mannosamine was 98 and 96\%, respectively. Conclusion. We were able to improve glucosamine assay suitable to quantify glucosamine in both human and rat plasma and rat urine.
\end{abstract}

\section{INTRODUCTION}

Glucosamine, 2-amino-2 deoxy-D-glucose, is a naturally occurring compound which is considered as an essential building block in the synthesis of the cartilage matrix. Except for some jurisdictions, it is considered as a dietary supplement although it is widely used in the treatment of osteoarthritis for its chondroprotective effect and anti-inflammatory action (1, 2). Moreover, glucosamine has a protective effect against atherosclerosis (3), an inhibitory effect on platelet activation and ability to improve organ function after trauma hemorrhage (3, 4). Although glucosamine has been used clinically since 1960s, its pharmacokinetics are not welldefined due, at least in part, to the lack of sensitive or facile assays. Glucosamine pharmacokinetic data are needed to help resolve the controversial data generated from various clinical trials (5). The compound is not regulated and it has been reported that many commercially available products do not contain the label-claimed active ingredient (6). The patients included in the reported clinical trials, therefore, might have been under-dosed.
As an amino sugar the compound lacks chromophores, hence, is undetectable in the ultraviolet-visible ranges. Early studies on glucosamine pharmacokinetic have been carried out using radio labeled compound which could not distinguish between the parent compound and its biosynthetic or degraded products (7). The first reported high performance liquid chromatography (HPLC) methods for determination of glucosamine in plasma were based on derivatization of glucosamine with phenylisothiocyanate (8) or 1naphthyisothicyanate (9) to form a compound that can be detected in the UV region. Those methods, however, lack sufficient sensitivity in the presence of human plasma $(>1.25 \mu \mathrm{g} / \mathrm{mL})$. More recently, sensitive liquid chromatography methods have been reported that involve detection of intact or derivatized glucosamine product by electrospray

Corresponding author: Fakhreddin Jamali, Faculty of Pharmacy \& Pharmaceutical Sciences, University of Alberta, Edmonton, Alberta, Canada, T6G 2N8;

fjamali@pharmacy.ualberta.ca 


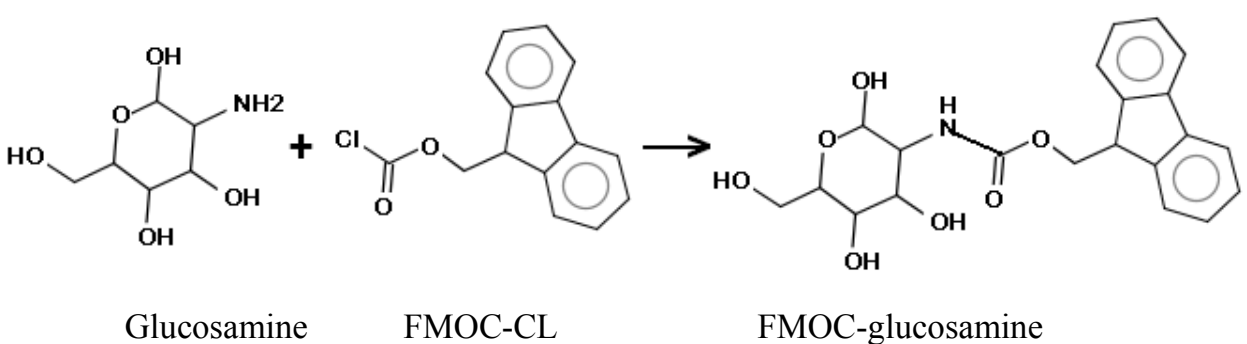

Figure 1. Formation of 9-fluorenylmethoxycarbonyl-glucosamine

ionization with mass spectroscopy (10-15). Suitable instruments for these assays, however, are not commonly available. In 2006, Zhang et al reported an HPLC method with florescence detection for determination of glucosamine in human plasma that involved derivatization with 9-fluorenylmethoxycarbonyl chloride (FMOC-CL) without using an internal standard (Figure 1) (16). The derivatization yields two anomers (stereoisomers of a cyclic sugars that differ in their configuration at the anomeric carbon) peaks (16). This method was later modified by Huang et al who added vertilmicin sulfate as an internal standard (17). The minimum quantifiable concentration of this method was $100 \mathrm{ng} / \mathrm{mL}$. Our attempts to utilize this method, however, failed due the presence of broad interfering peaks and elevation of the HPLC pump pressure following repeated injections. The goal of this work was to improve and optimize the reported method for determination of glucosamine in the rat and human biological fluids.

\section{EXPERIMENTAL}

\section{Material and Reagents}

Glucosamine $\mathrm{HCl}$, mannosamine $\mathrm{HCl}$, amantadine $\mathrm{HCl}$ (1-aminoadmantane $\mathrm{HCl}, \mathrm{ADAM}$ ) and FMOCCL were purchased from Sigma-Aldrich Canada, LTD, (Oakville, ON, Canada), HPLC grade acetonitrile and water were obtained from Caledon Laboratories Ltd, (ON, Canada).

\section{Solutions and standards}

Glucosamine stock solution was prepared by dissolving $60 \mathrm{mg}$ glucosamine $\mathrm{HCl}$ in $100 \mathrm{~mL}$ water to yield a $0.5 \mathrm{mg} / \mathrm{mL}$ solution of glucosamine free base. The stock solution was further diluted with water to give standard solution containing $0.05,0.1,0.25,0.5,1,2.5,5,10$ and $20 \mu \mathrm{g} / \mathrm{mL}$. Mannosamine was used as the internal standard (IS) for which a stock solution was prepared by dissolving the compound in water to give 10 $\mu \mathrm{g} / \mathrm{mL}$. The derivatizing reagent solution $(8 \mathrm{mM})$ was prepared freshly by dissolving $10.3 \mathrm{mg}$ FMOC$\mathrm{CL}$ in $5 \mathrm{~mL}$ acetonitrile. Borate buffer $0.2 \mathrm{M}$ was prepared by dissolving $6.18 \mathrm{~g}$ boric acid in $425 \mathrm{~mL}$ water followed by $\mathrm{pH}$ adjustment to 8.5 using $10 \mathrm{M}$ $\mathrm{NaOH}$. A $300 \mathrm{mM}$ solution of ADAM was prepared

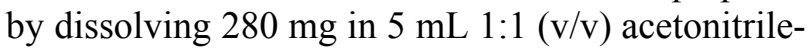
water.

\section{Sample preparation and derivatization}

Aliquot of $0.1 \mathrm{~mL}$ human or rat plasma was spiked with $50 \mu \mathrm{L}$ of $10 \mu \mathrm{g} / \mathrm{mL}$ IS. Plasma proteins were precipitated by addition of $200 \mu \mathrm{L}$ acetonitrile followed by 1 min vortex-mixing and centrifugation for $3 \mathrm{~min}$ at $10,000 \mathrm{~g}$ into clean test tubes; $100 \mu \mathrm{L}$ of the supernatant were transferred and $50 \mu \mathrm{L}$ of borate buffer were added followed by addition of 50 $\mu \mathrm{L}$ of freshly prepared FMOC-CL. This was followed by 1 min vertex-mixing and incubation in a water bath at $30^{\circ} \mathrm{C}$ for $30 \mathrm{~min}$. After incubation, $50 \mu \mathrm{L}$ of ADAM was added to the test tubes to react with the excess derivatizing agent. The samples were then diluted with $1 \mathrm{~mL}$ acetonitrilewater (1:1) and $5 \mu \mathrm{L}$ injected into the HPLC.

\section{Chromatographic conditions}

A Shimadzu prominence HPLC system (Mandel Scientific, Guelph, ON Canada) consisting of a DGU-20A5 degasser, a LC-20AT pump, a SIL-20A autosampler, a CTO-20AC column oven, a RF10AxL fluorescence detector and a CBM-20A communication bus module was used. The integration was performed using Shimadzu ClassVP 7.4 software. Chromatographic separation was achieved on Phenomenex C18 (100mm X $4.6 \mathrm{~mm}$, id $3 \mu \mathrm{m})$ reversed phase column guarded with Phenomenex Security Guard Cartridge $\mathrm{C}_{18}(4 \mathrm{~mm} x$ $3 \mathrm{~mm}$ ) column both purchased from Phenomenex 
(Torrance, CA USA). The mobile phase consisted of $0.1 \%$ glacial acetic acid in HPLC-grade water (A) and acetonitrile (B). A gradient elution was programmed to commence with $23 \%$ B for $13 \mathrm{~min}$ post-injection followed by gradual increase in $2 \mathrm{~min}$ of B to $90 \%$. The composition was maintained for 8 min when was gradually decreased back to $23 \%$ of $\mathrm{B}$ in $2 \mathrm{~min}$. The flow rate was $1 \mathrm{~mL} / \mathrm{min}$ and the column oven temperature was set at $40^{\circ} \mathrm{C}$. The detection was carried out at excitation and emission wavelength of $256 \mathrm{~nm}$ and $315 \mathrm{~nm}$, respectively. The sample run time was 35 min. The peak area was used on all calculations.

\section{Validation}

Calibration curves were prepared by spiking aliquots of $0.1 \mathrm{~mL}$ plasma with glucosamine to yield standard samples containing $0.05,0.5,5$ and $20 \mu \mathrm{g} / \mathrm{mL}$ of the compound. The standard curves were constructed by plotting glucosamine:IS peak area ratio versus the added concentration of glucosamine. Three calibration curves were constructed in the same day to determine intraday variability. The method was repeated on three different days to determine the interday variability. The accuracy was determined from $\%$ error $=($ mean observed concentration - added concentration) $\mathrm{x} 100 /$ added concentration. The coefficient of variation $(\mathrm{CV} \%)$ was used to estimate the assay precision.

\section{Recovery}

Solutions of $0.05,0.5,5$ and $20 \mu \mathrm{g} / \mathrm{mL}$ glucosamine were prepared in plasma and in water and analyzed as mentioned before, each in triplicate. The \% recovery of glucosamine from plasma was estimated from \% recovery $=$ (glucosamine peak area in plasma sample/glucosamine peak area in water sample) $x$ 100. The recovery of mannosamine from plasma was also determined using the same approach.

\section{Stability}

Short term stability. Stability of the samples during analysis was tested using 4 standard samples of glucosamine in plasma $(0.05,0.5,5$ and $20 \mu \mathrm{g} / \mathrm{mL})$. Samples were prepared and derivatized as mentioned before. They were analyzed at $0,4,8$ and $24 \mathrm{~h}$ after derivatization. The \% accuracy and $\% \mathrm{CV}$ were calculated.
Freeze and thaw stability. Four standard samples of glucosamine in plasma $(0.05,0.5,5$ and $20 u g / \mathrm{mL})$ were prepared and kept in the freezer at $-20^{\circ} \mathrm{C}$ for $24 \mathrm{~h}$. Samples were then removed from the freezer and allowed to thaw at room temperature. They were refrozen again for another $24 \mathrm{~h}$. Aliquots of the standard samples were derivatized and analyzed after each freeze-thaw cycle and the \% accuracy and $\mathrm{CV}$ were determined.

\section{Application}

The method was used to detect glucosamine in human plasma separated from blood collected from arms vain of a male adult 0,1 and $6 \mathrm{~h}$ after a single $1500 \mathrm{mg}$ oral dose of glucosamine sulfate (Webber Naturals, Coquitlam BC, Canada, Lot \# 567521), and in plasma of 5 rats separated from the jugular veins blood collected through surgically inserted catheters at $0,0.25,0.5,0.45,1,2.5,3,4,6$ and $8 \mathrm{~h}$ after single oral doses of $200 \mathrm{mg} / \mathrm{kg}$ glucosamine $\mathrm{HCl}$. We also collected the total urine output of the rats during $0-6 \mathrm{~h}$ post-dose.

\section{RESULTS}

The validation data generated using the rat and human were identical. Herein, therefore, the human data is presented. As expected $(13,14)$ both glucosamine and IS appeared as equal size pairs of resolved anomers peaks (Figures 2 and 3). The retention times were 10.6 and $13.1 \mathrm{~min}$ for mannosamine and 11.7 and $14.6 \mathrm{~min}$ for glucosamine peaks. There was no interfering peak in either spiked or post-dose samples except for an endogenous compound that appeared too close to glucosamine's first peak. Our attempt to resolve this interference resulted in broad peaks and elongation of the elution time. Hence, since the anomeric peaks of each of the two compounds were identical in size, we used the second peak of each compound for quantification.

The assay was found linear over the examined range of $0.05-20 \mu \mathrm{g} / \mathrm{mL}$ in human plasma with a typical regression equation of $\mathrm{y}=0.307 \mathrm{x}+0.003$ and a correlation coefficient of 0.999 . We set the lowest limit of quantification at $50 \mathrm{ng} / \mathrm{mL}$. The inter- and intra-day variations were less than $20 \%$ for the $50 \mathrm{ng} / \mathrm{mL}$ samples and less than $10 \%$ for other concentrations. The accuracy ranged from 1.72 to $2.46 \%$ (Table 1 ). 


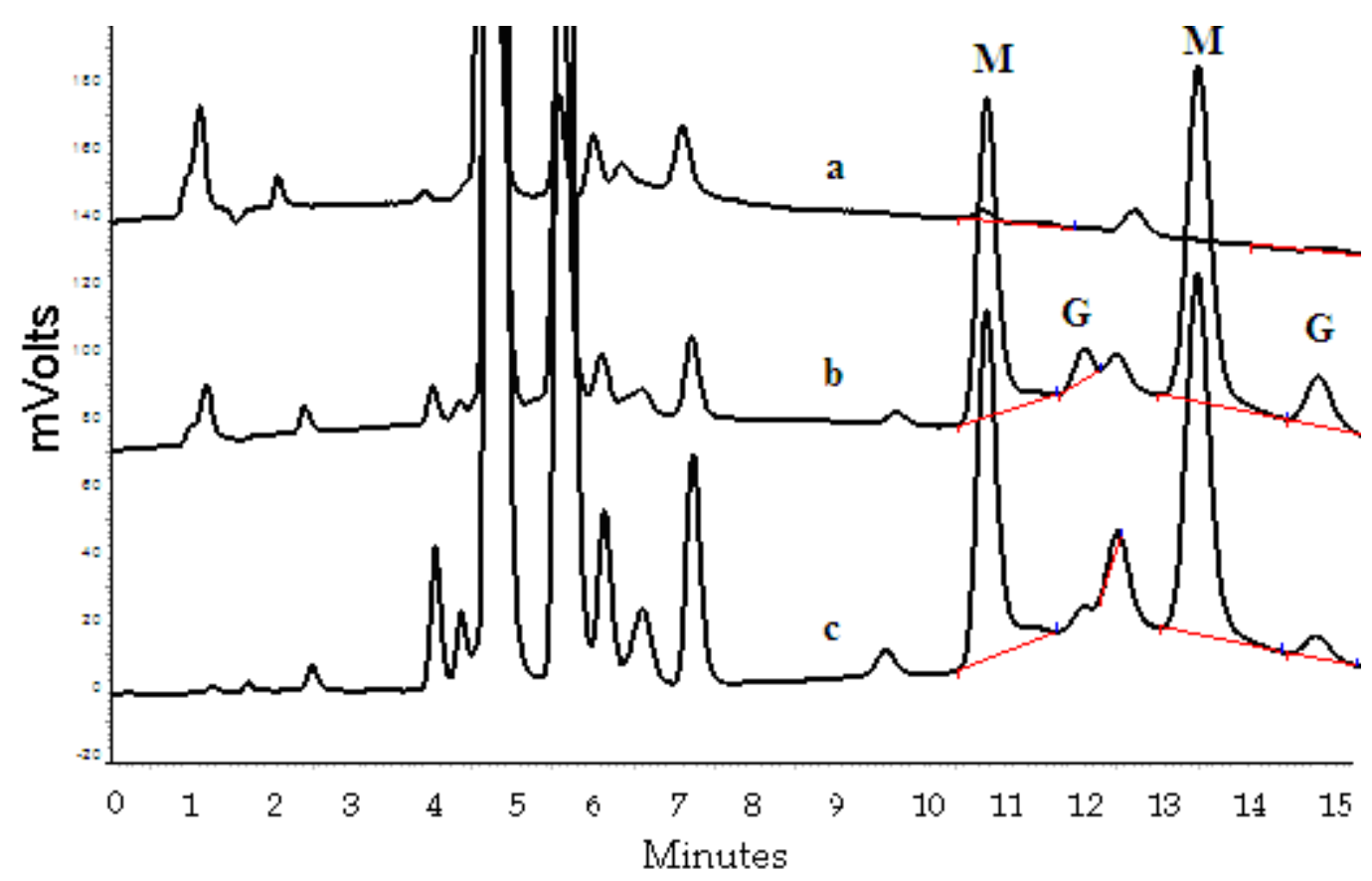

Figure 2. HPLC chromatogram of blank human plasma (a), blank human plasma spiked with 500 $\mathrm{ng} / \mathrm{mL}$ glucosamine (b) and plasma obtained from healthy volunteer $1 \mathrm{~h}$ after oral administration of 3 X500 mg glucosamine sulfate showing $180 \mathrm{ng} / \mathrm{mL}$ glucosamine (c). Keys: M, mannosamine; G, glucosamine

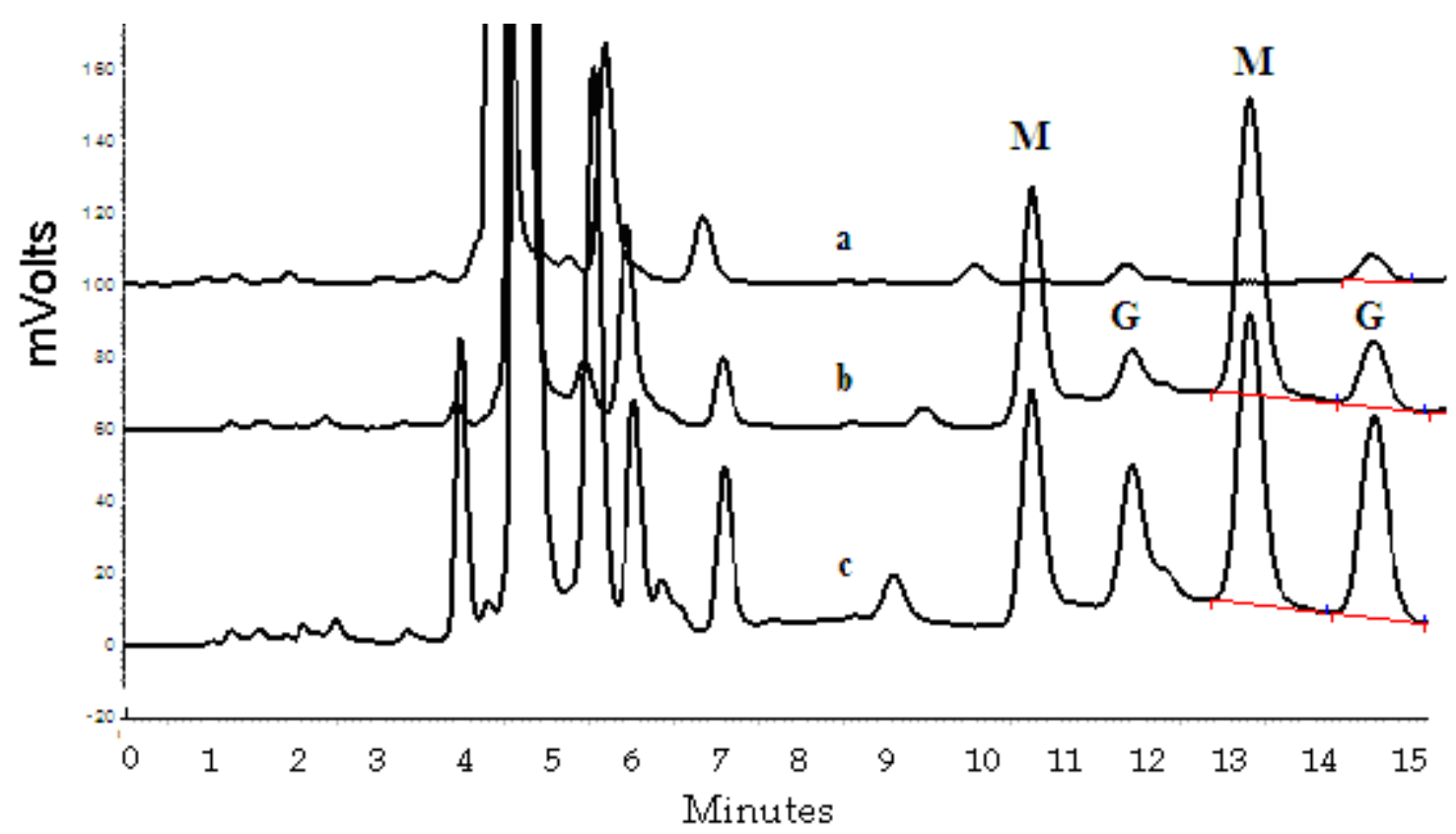

Figure 3. HPLC chromatogram of blank rat plasma (a), blank rat plasma spiked with $500 \mathrm{ng} / \mathrm{mL}$ glucosamine (b) and plasma obtained from rat $1 \mathrm{~h}$ after oral administration of $200 \mathrm{mg} / \mathrm{kg}$ glucosamine (c). Keys: M, mannosamine; G, glucosamine 
Table 1. Precision and Accuracy of glucosamine assay

\begin{tabular}{llll}
\hline \multicolumn{2}{l}{ Concentration, $\mu \mathrm{g} / \mathrm{mL}$} & $\mathrm{CV}$ & \multicolumn{2}{c}{ Accuracy } \\
\hline \multicolumn{2}{l}{ Added } & Observed & \multicolumn{2}{c}{ Percent } \\
\hline$\underline{\text { Intra-day }}$ & & & \\
0.05 & $0.051 \pm 0.001$ & 2.49 & 1.21 \\
0.5 & $0.49 \pm 0.02$ & 4.87 & -1.71 \\
5 & $4.92 \pm 0.20$ & 4.12 & -1.62 \\
20 & $20.49 \pm 0.48$ & 2.33 & 2.46 \\
& & & \\
Inter-day & & & \\
0.05 & $0.049 \pm 0.002$ & 4.86 & -1.72 \\
0.5 & $0.500 \pm 0.008$ & 1.63 & -0.03 \\
5 & $5.01 \pm 0.085$ & 1.70 & 0.14 \\
20 & $20.30 \pm 0.25$ & 1.24 & 1.49 \\
\hline
\end{tabular}

The percent recovery of glucosamine from plasma in the lowest, medium and highest concentration were determined to be $119 \pm 9.1$, $100 \pm 4.1,97.2 \pm 2.1$ and $98.2 \pm 1.8 \%$ for $0.05,0.5,5$ and $20 \mu \mathrm{g} / \mathrm{mL}$, respectively For mannosamine, the $\%$ recovery from plasma was $95.9 \pm 2$.

Derivatized glucosamine was found stable during analysis in all plasma samples (Table 2). It was also stable in plasma after three freeze and thaw cycles (Table 2).

Table 2. Stability of glucosamine in plasma

\begin{tabular}{lccc}
\hline \multicolumn{2}{l}{ Concentration, $\mu \mathrm{g} / \mathrm{mL}$} & $\mathrm{CV}$ & Accuracy \\
\hline \multicolumn{2}{l}{ Added } & Observed & \multicolumn{2}{c}{ Percent } \\
\hline Short term, 24 h & & \\
0.05 & $0.058 \pm 0.01$ & 11.2 & 12.7 \\
0.5 & $0.48 \pm 0.01$ & 1.41 & 0.5 \\
5 & $4.91 \pm 0.08$ & 1.54 & -1.7 \\
20 & $20.7 \pm 0.54$ & 2.63 & -1.3 \\
\multicolumn{4}{l}{ Freeze-thaw stability, } \\
3 cycles freezing at $-20^{\circ} \mathrm{C}$ & & \\
0.05 & $0.051 \pm 0.01$ & 9.10 & 10.78 \\
0.5 & $0.52 \pm 0.03$ & 6.55 & -3.08 \\
5 & $4.90 \pm 0.06$ & 1.21 & -1.32 \\
20 & $20.2 \pm 0.05$ & 0.25 & 0.28 \\
\hline
\end{tabular}

In human plasma, the baseline glucosamine was below the detection limit. A single $1500 \mathrm{mg}$ oral dose of glucosamine yielded plasma concentrations of 184 and $42 \mathrm{ng} / \mathrm{mL}$ at 1 and $6 \mathrm{~h}$ post-dose (Figure2). In the rat plasma, glucosamine concentration over the $8 \mathrm{~h}$ post-dose period ranged from 7.43 to $0.10 \mu \mathrm{g} / \mathrm{mL}$ that was within the sensitivity of the method (Figure 4).

We did not carry out detailed validation tests for glucosamine in urine. However, the calibration curves generated using spiked rat urine samples were identical to those observed when the compound was tested in water. In the rat urine, after 10 times dilution of the samples, glucosamine concentration ranged from $13-27 \mu \mathrm{g} / \mathrm{ml}$ which account for $1.2 \pm 0.42 \%$ of the administered dose excreted unchanged in the urine in $6 \mathrm{~h}$ post-dose. The anomers were resolved except for the first peak of glucosamine that, as observed in the presence of plasma, eluted along with an interfering peak.

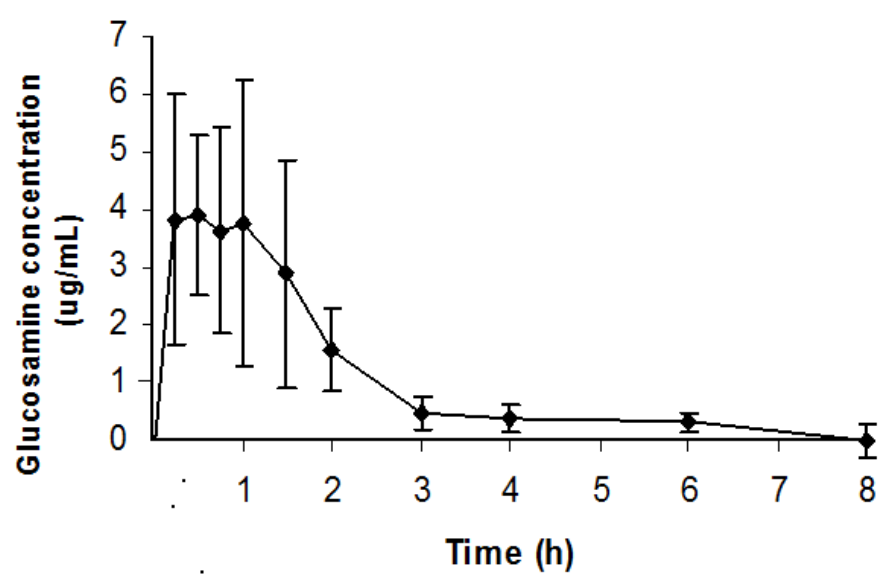

Figure 4. Mean plasma concentration of glucosamine in rat $(n=5)$ after oral administration of $200 \mathrm{mg} / \mathrm{kg}$ dose.

\section{DISCUSSION}

As a derivatizing agent, FMOC-CL has been used since 1980s for HPLC analysis of amino acids (18, 19). The advantage of this compound is its ability to rapidly react in alkaline media with primary and secondary amines and form a highly fluorescence derivative. In our attempts to conduct a detailed pharmacokinetic study on glucosamine, we used a previously reported method that involved formation of an FMOC-glucosamine derivative (16).

Application of this method gave us a crowded chromatogram in which glucosamine peaks were trapped between two large peaks of the endogenous compounds. Upon repeated injections, the large peaks overlapped with glucosamine. This was accompanied by an elevation in the column pressure. Moreover, the recovery of glucosamine from plasma samples was only $38 \%$. Attempts to 
improve the recovery by increasing the amount of the derivatizing agent resulted in more interfering peaks. In the reported methods for determination of amino acids after derivatization with FMOC-CL, the aqueous part of the mobile phase has generally been an acetate buffer rendering the acidic analytes (amino acids) less polar, hence, allowing longer retentions on the reversed phase column. Our replacement of the acetate buffer with $0.1 \%$ acetic acid in HPLC water resulted in cleaner and more reproducible chromatograms (Figures 2 and3). In the meantime, we decreased the percentage of acetonitrile in the first $13 \mathrm{~min}$ from $30 \%$ to $23 \%$ to allow maximum separation of the peaks.

Huang et al reported that FMOC-CL precipitated when acetonitrile concentration dropped below $30 \%$. To avoid precipitation we injected aliquots of only $5 \mu \mathrm{L}$ of samples after dilution with 1:1 acetonitrile-water.

Under our conditions, most of the plasma interfering peaks eluted after the appearance of mannosamine $\mathrm{HCl}$ that we used as the internal standard. Mannosamine has a chemical structure and physical properties similar to glucosamine except in the amino group at the position 2. This group is equatorial in glucosamine and axial in mannosamine, hence, provides a different three dimensional orientation and facilitate efficient HPLC separation of the two compounds (20). Reaction with FMOC-CL adds a large molecule at position 2 and obtains a steric hindrance that prevents the possibility of inter-conversion between glucosamine and mannosamine.

For the amino acid analysis, the excess derivatizing agent has been generally removed by extraction with pentane or by reaction with ADAM to form a hydrophobic complex that elutes towards the end of the run time (21). Since glucosamine is a weak base and FMOC-CL and FMOC-glucosamine peaks are eluted at different times, Zhang et al (16) and Huang et al (17) did not need to apply the sample cleaning step. However, under our experimental condition, we noticed a small peak that interfered with that of glucosamine. This interfering peak was eliminated when we added ADAM. In addition, the sample cleaning rendered the baseline more stable even after doubling the amount of FMOC-CL (from $4 \mathrm{mM}$ to $8 \mathrm{mM}$ ) that enable us to achieve a lowest limit of quantification at $50 \mathrm{ng} / \mathrm{mL}$ and a percent recovery of $98 \%$ and
$96 \%$ for glucosamine and mannosamine, respectively.

The method is both accurate and reproducible. It also is more sensitive than some of the reported methods [e.g., (9)] and provides more facile procedure than others $(10-12,14,17)$. The application of the assay in pharmacokinetic studies of glucosamine in the rat allowed analysis of plasma concentrations up to $8 \mathrm{~h}$ post-dose. In our previous report we had analyzed pharmacokinetics of glucosamine only up to $4 \mathrm{~h}$ due to the lack of sensitivity (22). The previously reported methods including ours (9) did not detect baseline glucosamine concentrations in the rat due to the inherit lack of sensitivity. In the present study, on the other hand, we did observed baseline glucosamine levels but were generally low (see the $8 \mathrm{~h}$ value in Figure 4) but as high as $250 \mathrm{ng} / \mathrm{mL}$ in a single rat. Such an example is presented in Figure3. This may render the reliability of the post $4 \mathrm{~h}$ concentration questionable. We did not correct for the baseline values as we were not certain of the consistency of the endogenous baseline levels during the $8 \mathrm{~h}$ experiment. This is inevitable with sensitive assays developed for the determination of endogenous compounds. For glucosamine, the post $4 \mathrm{~h}$ concentrations are rather low, hence, their contribution to the overall area under the curve should be negligible; however, they may introduce error in calculation of the compound's terminal half-life. The assay is also suitable for the measurement of glucosamine in human plasma. We detected no baseline glucosamine in the pre-dose human sample. Jackson et al (23) and Zhong et al (11) also did not detect baseline glucosamine concentrations in their subjects. Roda et al (12), on the other hand, have reported a mean of $64 \pm 47$ $\mathrm{ng} / \mathrm{mL}$ endogenous glucosamine. It is worthy of mentioning that Roda et al's reported overall glucosamine concentrations (12) are substantially greater that those reposted by Jackson et al (23), and Zhong et al (11). Nevertheless, similar to what we have observed in the rat (Figure3), the possibility of endogenous glucosamine must also be considered for interpretation of human plasma samples containing low concentrations of the compound.

We did not completely validate glucosamine assay in urine. Nevertheless, this is the first reported HPLC method for determination of unchanged glucosamine in urine samples. The total 
glucosamine excreted in human urine in $3 \mathrm{~h}$ has previously been determined by ion exchange chromatography with amperometric detection to be less than $1 \%$ of the administered dose (24). Our results suggest $1.2 \%$ cumulative urinary excretion in the rat over $6 \mathrm{~h}$ following oral doses to rats. In this context, it is important to consider the relative bioavailabity of oral glucosamine doses (9).

Glucosamine concentration in human plasma appears to be dependent on the administered product. The reported values following $1500 \mathrm{mg}$ glucosamine as hydrochloride (23) or sulfate (25) are approximately three-fold different from each other. We found 184 and $42 \mathrm{ng} / \mathrm{mL}$ of glucosamine in plasma of a man following a single $1500 \mathrm{mg}$ oral dose of the sulfate salt. The $6 \mathrm{~h}$ sample was below the set sensitivity of the assay, i.e., $50 \mathrm{ng} / \mathrm{mL}$. However, we injected only $5 \mu \mathrm{L}$ of the final solution to prevent pump pressure build-up. An increased volume of injection of only those samples with lower concentration, however, is not expected to cause pressure build-up but will improve the assay sensitivity. Our observed concentrations in human plasma samples are in agreement with those reported by Jackson et al (23). Nevertheless, the method offers sensitivity within the reported concentration ranges.

\section{CONCLUSION}

Herein we present an improved assay of glucosamine in biological fluids suitable for pharmacokinetic studies. The assay has a reliable sensitivity for concentrations above $50 \mathrm{ng} / \mathrm{mL}$ based on $5 \mu \mathrm{L}$ of injection volume onto HPLC. The assay sensitivity, however, can be improved using larger injection volumes.

\section{ACKNOWLEDGEMENT}

$\mathrm{AI}$ is a recipient of an Egyptian government scholarship. This work was supported by a grant from the Canadian Foundation for Innovation.

\section{REFERENCES}

1. Black C, Clar C, Henderson R, et al. The clinical effectiveness of glucosamine and chondroitin supplements in slowing or arresting progression of osteoarthritis of the knee: a systematic review and economic evaluation. Health Technol Assess. 2009;13:1-148.
2. Kim MM, Mendis E, Rajapakse N, Kim SK. Glucosamine sulfate promotes osteoblastic differentiation of MG-63 cells via anti-inflammatory effect. Bioorg Med Chem Lett. 2007;17:1938-42.

3. Duan W, Paka L, Pillarisetti S. Distinct effects of glucose and glucosamine on vascular endothelial and smooth muscle cells: evidence for a protective role for glucosamine in atherosclerosis. Cardiovasc Diabetol. 2005;4:16.

4. Yang S, Zou LY, Bounelis P, Chaudry I, Chatham JC, Marchase RB. Glucosamine administration during resuscitation improves organ function after trauma hemorrhage. Shock. 2006;25:600-7.

5. Vlad SC, LaValley MP, McAlindon TE, Felson DT. Glucosamine for pain in osteoarthritis: why do trial results differ? Arthritis Rheum. 2007;56:2267-77.

6. Russell AS, Aghazadeh-Habashi A, Jamali F. Active ingredient consistency of commercially available glucosamine sulfate products. J Rheumatol. 2002;29:2407-9.

7. Setnikar I, Giacchetti C, Zanolo G. Pharmacokinetics of glucosamine in the $\operatorname{dog}$ and in man. Arzneimittelforschung. 1986;36:729-35.

8. Liang Z, Leslie J, Adebowale A, Ashraf M, Eddington ND. Determination of the nutraceutical, glucosamine hydrochloride, in raw materials, dosage forms and plasma using pre-column derivatization with ultraviolet HPLC. J Pharm Biomed Anal. 1999;20:807-14.

9. Aghazadeh-Habashi A, Sattari S, Pasutto F, Jamali F. High performance liquid chromatographic determination of glucosamine in rat plasma. J Pharm Pharm Sci. 2002;5:176-80.

10. Beaudry F, Vachon P. Determination of glucosamine in horse plasma by liquid chromatography tandem mass spectrometry. Biomed Chromatogr. 2008;22:1-4.

11. Zhong S, Zhong D, Chen X. Improved and simplified liquid chromatography/ electrospray ionization mass spectrometry method for the analysis of underivatized glucosamine in human plasma. J Chromatogr B Analyt Technol Biomed Life Sci. 2007;854:291-8.

12. Roda A, Sabatini L, Barbieri A, et al. Development and validation of a sensitive HPLC-ESI-MS/MS method for the direct determination of glucosamine in human plasma. J Chromatogr B Analyt Technol Biomed Life Sci. 2006;844:119-26.

13. Cheng X, Liao $\mathrm{YH}, \mathrm{Ge} \mathrm{H}$, et al. TH1/TH2 functional imbalance after acute myocardial infarction: coronary arterial inflammation or myocardial inflammation. J Clin Immunol. 2005;25:246-53.

14. Yu Y, Cai L, Zuo M, Duan G. Precolumn derivatization liquid chromatography with mass spectrometry assay for the determination of 
glucosamine in small volume human plasma. Ann Chim. 2005;95:709-13.

15. Huang TM, Cai L, Yang B, Zhou MX, Shen YF, Duan GL. Liquid chromatography with electrospray ionization mass spectrometry method for the assay of glucosamine sulfate in human plasma: validation and application to a pharmacokinetic study. Biomed Chromatogr. 2006;20:251-6.

16. Zhang LJ, Huang TM, Fang XL, et al. Determination of glucosamine sulfate in human plasma by precolumn derivatization using high performance liquid chromatography with fluorescence detection: its application to a bioequivalence study. J Chromatogr B Analyt Technol Biomed Life Sci. 2006;842:8-12.

17. Huang TM, Deng CH, Chen NZ, Liu Z, Duan GL. High performance liquid chromatography for the determination of glucosamine sulfate in human plasma after derivatization with 9-fluorenylmethyl chloroformate. J Sep Sci. 2006; 29 (15):2296-302.

18. Einarsson S, Josefsson $\mathrm{B}$, Lagerkvist $\mathrm{S}$. Determination of amino acids with 9-fluorenylmethyl chloroformate and reversed-phase highperformance liquid chromatography. Journal of Chromatography A. 1983;282:609-618.

19. Golaz O, Wilkins MR, Sanchez JC, Appel RD, Hochstrasser DF, Williams KL. Identification of proteins by their amino acid composition: an evaluation of the method. Electrophoresis. 1996; 17:573-9.

20. Desaire H, Leary JA. Multicomponent quantification of diastereomeric hexosamine monosaccharides using ion trap tandem mass spectrometry. Anal Chem. 1999;71:4142-7.

21. Gustavsson B, Betner I. Fully automated amino acid analysis for protein and peptide hydrolysates by precolumn derivatization with 9-fluorenylmethyl chloroformate and 1-aminoadamantane. J. Chromatogr. 1990; 507:67-77.

22. Aghazadeh-Habashi A, Sattari S, Pasutto F, Jamali F. Single dose pharmacokinetics and bioavailability of glucosamine in the rat. J Pharm Pharm Sci. 2002;5:181-4.

23. Jackson CG, Plaas AH, Sandy JD, et al. The human pharmacokinetics of oral ingestion of glucosamine and chondroitin sulfate taken separately or in combination. Osteoarthritis Cartilage. 2009; 18: 297-302.

24. Biggee BA, Blinn CM, McAlindon TE, Nuite M, Silbert JE. Low levels of human serum glucosamine after ingestion of glucosamine sulphate relative to capability for peripheral effectiveness. Ann Rheum Dis. 2006;65:222-6.

25. Persiani S, Roda E, Rovati LC, Locatelli M, Giacovelli G, Roda A. Glucosamine oral bioavailability and plasma pharmacokinetics after increasing doses of crystalline glucosamine sulfate in man. Osteoarthritis Cartilage. 2005;13:1041-9. 